\title{
Influence of S. cerevisiae and P. kluyveri as starters on chocolate flavour
}

\author{
Igor Moreira, ${ }^{a}$ Jéssica Costa, ${ }^{b}$ Leonardo Vilela, ${ }^{c}$ Nelson Lima, ${ }^{d}$ \\ Cledir Santos $^{\mathrm{e}^{*} \odot \text { and Rosane Schwanc }}$
}

\begin{abstract}
BACKGROUND: Fermented cocoa beans (Theobroma cacao L.) are a pivotal raw material for chocolate production. A cocktail yeast applied in the cocoa fermentation process can promote the formation of pleasant metabolites. Saccharomyces, Pichia and Hanseniaspora have been widely used in fermentation to improve the final product organoleptic profile, highlighting that fermentation is a critical point for chocolate flavour precursor production. This study aims to evaluate the impact of Pichia kluyveri and Saccharomyces cerevisiae strains as starter cultures on the fermentation for two cocoa hybrids, FA13 and CEPEC2002.
\end{abstract}

RESULTS: During fermentation processes, volatile organic compounds (VOCs) and protein profiles were assessed. Chocolates produced were also assessed regarding the presence of VOCs. Eighty VOCs were identified using gas chromatography coupled to mass spectrometry analysis. Mass spectrometry provided the protein profile evolution during fermentation and showed that the profiles changed with inoculation type (spontaneous versus inoculated fermentation). Chocolate obtained from FA13 inoculated with S. cerevisiae strain contained a greater amount of organics acids, being categorised as sourer than chocolate produced by spontaneous fermentation of FA13. CEPEC2002 inoculated with S. cerevisiae strain in co-culture with P. kluyveri strain generated less sour and sweeter chocolate than spontaneous fermentation only.

CONCLUSIONS: Chocolates from inoculated assays with starter cultures were more accepted by evaluators, highlighting that P. kluyveri and S. cerevisiae influence the composition of VOCs. Besides, protein profiles also changed throughout fermentation. Further investigation should be conducted to clarify protein degradation dynamics during inoculated fermentations to define which of the microbial cultures positively affect the chocolate sensory characteristics.

(c) 2021 Society of Chemical Industry

Supporting information may be found in the online version of this article.

Keywords: cocoa fermentation; GC-MS; MALDI-TOF MS; protein profile; yeast co-culture

\section{INTRODUCTION}

Cocoa beans are a pivotal raw material for many food products such as cocoa paste, butter, powder, liquor and chocolate. ${ }^{1}$ Overall, global food industries direct the majority of cocoa bean yield to chocolate manufacture, which accounts for more than $45 \%$ of output. $^{2}$ This is due mainly to widespread chocolate consumption with large growth potential. In 2020, the global chocolate market was forecast to reach USD137.12 billion. ${ }^{2}$ Moreover, by 2026, growth is expected to reach USD189.89 billion. ${ }^{2}$ For that, it is of utmost necessity to improve and control the processing of each step of the chocolate production chain seeking to meet the market sensorial requirement demands.

High-quality chocolate production is directly reliant on an efficient fermentation process since flavour precursors are formed in this step. Before fermentation, cocoa bean is astringent and bitter, and therefore unfeasible for post-harvest processing (e.g. roasting and conching steps). ${ }^{3}$

Generally, cocoa fermentation is conducted spontaneously by the action of natural microbiota. ${ }^{4}$ Under uncontrolled operating conditions, these microorganisms can be provided by contact with operators' hands and tools. Besides, microorganisms are naturally present on the surface of cocoa pods. ${ }^{5}$ In spontaneous fermentation, a random fluctuation in inoculum is expected, since there is no real control of the natural microbiota composition harboured by each cocoa breed or of the microbiota that can be added by external factors. Hence, the fermentation process can be subjected to variations. ${ }^{6}$

Conversely, controlled fermentation processes use a defined cocktail of microorganisms, optimising the fermentation

* Correspondence to: C Santos, Department of Chemical Science and Natural
Resources, Universidad de La Frontera, Temuco 4811-230, Chile. E-mail: cledir.santos@ufrontera.cl

a Department of Food Science, Federal University of Lavras, Lavras, Brazil

b Programa de Doctorado en Ciencias de Recursos Naturales, Universidad de La Frontera, Temuco, Chile

c Department of Biology, Federal University of Lavras, Lavras, Brazil

d CEB-Centre of Biological Engineering, Micoteca da Universidade do Minho, University of Minho, Braga, Portugal

e Department of Chemical Science and Natural Resources, Universidad de La Frontera, Temuco, Chile 
timeframe, and minimising the presence of spoilage organisms. The use of a standardised process provides a feasible condition to achieve a high-quality product. ${ }^{6}$

The microorganism dynamic of cocoa bean fermentation is complex, and thus is essential broaden knowledge of the role of each microbial group. The main microbial groups found in fermentation processes are yeasts, lactic acid bacteria (LAB) and acetic acid bacteria $(A A B){ }^{6}$ Yeasts are dominant in the early stages and, subsequently, are surpassed by $L A B$ and $A A B .^{6-9}$ The functional roles of $L A B$ and $A A B$ in cocoa bean processing have been much discussed, ${ }^{10-12}$ but are not the focus of this study.

Saccharomyces cerevisiae has been widely applied as a starter yeast in the fermentation of cocoa beans, either alone in the process $^{13}$ or in co-culture with other yeasts such as Candida, Hanseniaspora (anamorph Kloeckera), Pichia and Torulaspora. ${ }^{14-17}$

The real fermentation takes place in the mucilaginous fruit pulp that surrounds the cocoa beans. This sugar-rich substrate boosts yeast growth, triggering alcoholic fermentation of the pulp sugars into ethanol and also pectinolytic enzymes. ${ }^{6}$

Proteolytic reactions inside the beans during fermentation are responsible for releasing small peptides and free amino acids considered as flavour precursors of the final produced chocolate. ${ }^{18}$ In addition, esters and higher alcohols produced by yeast during fermentation have been reported, potentially contributing to the volatile compound admixture. ${ }^{19}$

Various volatile organic compounds (VOCs) such as carboxylic acids, esters, aldehydes, alcohols and ketones that are produced during fermentation influence directly the chocolate sensory attributes. ${ }^{18,20}$ Microbiota strains involved, proteins and VOC profiles released during the fermentation process will be crucial factors for the production of chocolate of high quality. ${ }^{13,15,16,18,20}$

Previous studies have investigated the influence of yeast inoculation on the volatile and non-volatile composition, microbial community and sensory profile of chocolate. ${ }^{8,9,20,21}$ A proper understanding of the microbial dynamic in cocoa fermentation, mainly the role of yeasts, must be broadened. Despite this, up to now a microbial cocktail suitable as a starter culture for application in chocolate production has not been defined and marketed. ${ }^{10}$

The study presented here aimed to use Pichia kluyveri CCMAUFLA 0237 and Saccharomyces cerevisiae CCMA-UFLA 0200 strains as starters for fermentation of cocoa beans from the hybrids FA13 and CEPEC2002, and to evaluate the sensorial characteristics of chocolate produced in relation to the physicochemical changes, such as protein profile combined with VOCs.

\section{MATERIALS AND METHODS}

\section{Sampling, inoculation and fermentation}

The field experiments were conducted at Igrapiúna, BA, Brazil. Ripe cocoa beans (Theobroma cacao L.) from CEPEC2002 and FA13 hybrids were harvested from September to December 2014. Physical characteristics of each hybrid are presented in Table S1 (supporting information).

After harvesting, cocoa pods from CEPEC2002 and FA13 hybrids were manually opened with a machete, and the beans were transferred to the fermentation site. The fermentation began approximately $3 \mathrm{~h}$ after the pods were broken and was performed in $0.06 \mathrm{~m}^{3}$ wooden boxes; this point was considered as T0 of fermentation. $^{22}$ Each fermentation batch included $100 \mathrm{~kg}$ of cocoa beans. From these, $25 \mathrm{~g}$ of each hybrid was analysed in triplicate.
Fermentations were assessed using inoculation of CEPEC2002 with S. cerevisiae CCMA-UFLA 0200 in co-culture with P. kluyveri CCMA-UFLA 0237 and FA13 with S. cerevisiae CCMA-UFLA 0200 as single inoculum. Four fermentations were conducted: CEPEC2002 SP (S. cerevisiae and P. kluyveri), CEPEC2002 (control/ spontaneous fermentation), FA13 S (S. cerevisiae) and FA13 (control/spontaneous fermentation).

Both S. cerevisiae and $P$. kluyveri strains were obtained from CCMA-UFLA Culture Collection (Lavras/Brazil, WDCM 1083). S. cerevisiae CCMA-UFLA 0200 is commercialised by LNF (CA11) and was assessed according to the manufacturer's instructions. Based on this, S. cerevisiae was mixed in solution to reach a population of approximately $10^{7}$ cells per gram of cocoa. P. kluyveri was grown on yeast extract-peptone-dextrose broth $\left(10 \mathrm{~g} \mathrm{~L}^{-1}\right.$ yeast extract; $20 \mathrm{~g} \mathrm{~L}^{-1}$ peptone; $20 \mathrm{~g} \mathrm{~L}^{-1}$ dextrose) at $30{ }^{\circ} \mathrm{C}$ and replicated every $24 \mathrm{~h}$. The cells were recovered by centrifugation $(11000 \times g, 10 \mathrm{~min})$ and re-suspended in $1 \mathrm{~L}$ of sterile peptone water ( $1 \mathrm{~g} \mathrm{~L}^{-1}$ peptone; Himedia, Mumbai, India). This solution was applied to cocoa fermentation, reaching a concentration of approximately $10^{5}$ cells per gram of cocoa. ${ }^{23}$

The fermentations were performed in triplicate, with the analyses being performed every $24 \mathrm{~h}$ during 6 consecutive days (144 h). All samples were taken approximately $40 \mathrm{~cm}$ from the surface of the centre of the fermenting cocoa mass, placed in sterile plastic pots and stored at $-20^{\circ} \mathrm{C}$. The fermentation results represent the mean \pm standard error of three independent experiments.

\section{Analysis of VOCs using gas chromatography coupled to mass spectrometry}

The headspace-solid-phase microextraction (HS-SPME) technique combined with gas chromatography-mass spectrometry (GC-MS) was used for the analysis of VOCs from cocoa samples. ${ }^{7,23}$ Analyses were performed for each sample from the beginning $(0 \mathrm{~h})$ and at the end of the fermentation process (144 h). Extraction and analysis conditions were applied as previously described by Moreira et al. ${ }^{21}$.

VOCs from each headspace analysis were defined by integrating the peak areas of all the identified compounds. The relative percentages of individual compounds were calculated from the total contents of VOCs in the chromatograms. ${ }^{24}$

\section{Determination of protein profiles \\ Purification of protein samples}

Before conducting matrix-assisted laser desorption ionization time-of-flight (MALDI-TOF) MS analysis, samples from the beginning and end ( 0 and $144 \mathrm{~h}$ ) of each fermentation were subjected to extraction of lipids and polyphenols. This purification allowed removal of interfering substances such as lipids or phenolic compounds. Lipids were extracted from cocoa beans ( $c a 6.0 \mathrm{~g}$ ) that were crushed with liquid nitrogen and then extracted with $n$-hexane in a Soxhlet system as previously described by Voigt and Biehl. ${ }^{25}$ After $6 \mathrm{~h}$, lipid fraction was obtained using a rotary evaporator.

For polyphenol extraction, an acetone powder of defatted cocoa beans was obtained as previously reported. ${ }^{21}$ Each sample $(3 \mathrm{~g})$ was successively treated with $70 \%$ and $80 \%$ aqueous acetone, and $60 \mathrm{~mL}$ of neat acetone (sufficient to cover the sample). In each step, acetone suspensions were then supplemented with ascorbic acid $\left(5 \mathrm{mmol} \mathrm{L}^{-1}\right)$. Each mixture was stirred for $20 \mathrm{~min}$ using a vortex and then centrifuged at $30000 \times g$ for $20 \mathrm{~min}$ at $4{ }^{\circ} \mathrm{C}$ for recovering the pellet. 


\section{MALDI-TOF MS analyses of proteins}

After the lipid and polyphenol extraction, each sample $(0.5 \mathrm{~g})$ was crushed with a mortar and pestle using liquid nitrogen until a fine powder was obtained. Each sample was transferred to tubes containing $2 \mathrm{~mL}$ of solution A composed of water-acetonitriletrifluoroacetic acid (50:47.5:2.5 by volume) that were immediately stirred using a vortex for $10 \mathrm{~min}$. To improve protein extraction, glass beads were used. Tubes were centrifuged at $17000 \times g$ for 2 min at $4{ }^{\circ} \mathrm{C}$ and protein concentration in the supernatant was assessed by Bradford's method. ${ }^{26}$

Suspensions $(1 \mu \mathrm{L})$ were transferred to the MALDI-TOF sample plate (Bruker Daltonics, Bremen, Germany) and $1 \mu \mathrm{L}$ of saturated matrix solution of $\alpha$-cyano-4-hydroxycinnamic acid prepared with solution A described above was added and mixed. ${ }^{27-29}$ Spectra were acquired with a MALDI-TOF Microflex LT (Bruker Daltonics, Bremen, Germany) using the mass range from 2000 to $20000 \mathrm{Da}$.

Calibration of the MALDI-TOF equipment was performed using freshly in situ extracted ribosomal proteins of $E$. coli strain $\mathrm{DH} 5$-alpha, as previously described by Matos et al. ${ }^{30}$ and Paziani et al. ${ }^{31}$ Cells of $E$. coli DH5-alpha were grown on nutrient agar medium (Merck) at $37{ }^{\circ} \mathrm{C}$ for $20 \mathrm{~h}$. Briefly, fresh E. coli DH5-alpha biomass was transferred to MALDI sample plate and MALDI matrix solution was added and mixed. To evaluate reproducibility, each sample was applied in triplicate.

Raw spectra mzXML data were pre-processed and analysed using Mass-up software, following a previously published protocol. $^{32}$ Treatment of spectral data involved establishing parameters as previously described by Moreira et al. ${ }^{33}$

\section{Sensorial analysis}

Dried cocoa beans from different hybrids were used for chocolate production and the final moulded chocolate composed of $70 \%$ cocoa was wrapped and kept at $4{ }^{\circ} \mathrm{C}$ until sensory analysis. Sensory analyses of chocolates obtained from controls and inoculated fermentations were evaluated using a consumer acceptance test followed by a check-all-that-apply (CATA) questionnaire. Seventy-one people over 18 years old (59\% female and $41 \%$ male), non-professional tasters, participated in the CATA test. Participants were often untrained consumers of dark chocolate.

Consumers indicated in the acceptance test their satisfaction regarding each sample using a 9-point hedonic scale ( 1 = dislike extremely and $9=$ like extremely). ${ }^{34}$ In the CATA questionnaire the consumers evaluated seven chocolate sensorial attributes (astringent, bitter, coffee, fruity, nutty, sour and sweetness) and selected those considered appropriate to describe each chocolate sample. Tests were carried out as previously described by Batista et al. ${ }^{19}$

\section{Statistics}

All statistical analyses were performed using SISVAR 5.1 software (Federal University of Lavras, Department of Statistics, Lavras, Brazil). Analysis of variance (ANOVA) was used for the data obtained from both the acceptance testing and protein quantification analysis. Test of Tukey ( $5 \%$ significance level) was employed to compare the means.

To establish the agglomerative hierarchical clustering (AHC), XLSTAT software (version 7.5.2) was used. AHC was obtained using results of Biomarker Discovery analysis (presence and absence of ion peaks). Pearson correlation coefficient was used for showing similarities among samples.

\section{RESULTS}

\section{Chemical changes during fermentation}

Temperatures of inoculated fermentations increased rapidly over time, ranging from $25^{\circ} \mathrm{C}$ at $0 \mathrm{~h}$ to $48^{\circ} \mathrm{C}$ at $96 \mathrm{~h}$ (Fig. 1). A sharp increase in temperature occurred between the second and third days. The FA13 inoculated fermentation (FA13 S) showed a maximum temperature at $96 \mathrm{~h}\left(48.1^{\circ} \mathrm{C}\right)$. After $72 \mathrm{~h}$, a continues and slower rise of temperature was observed in all fermentation treatments, mainly for CEPEC2002 SP and FA13 S. All fermentations exhibited a plateau $(120 \mathrm{~h})$ with temperatures up to $47.5^{\circ} \mathrm{C}$.

\section{Volatile organic compounds}

A total of 80 different VOCs were identified using HS-SPME GC-MS analysis. These compounds were identified as 9 acids, 22 alcohols, 26 aldehydes and ketones, 19 esters and 4 other compounds (including pyrazines, pyrroles and terpenes) (Table 1).

The distribution of the 80 VOCs varied according to the sample evaluated. At the beginning of fermentation, a total of $31 \mathrm{com}-$ pounds were identified in both spontaneous and inoculated fermentations of CEPEC2002 hybrid. The profiles of aldehydes, ketones, pyrazines and other esters were closely similar for both treatments with CEPEC2002 and FA13 hybrids.

Among the VOCs, some of the common compounds identified were flavour-desirable ones, such as 3-methyl-1-butanol, 2,3-butanediol and 2-heptanol. Off-flavour acid compounds such as isobutyric acid, isovaleric acid and propanoic acid were also identified at the end of both fermentation processes. Conversely, phenylethyl alcohol, 1-butanol and ethyl benzoate were observed exclusively in CEPEC2002 SP. Other volatiles such as acetic acid were detected in the chocolates as well in T0 of CEPEC2002 SP and FA13 S fermentations.

FA13 S presented 40 compounds at the beginning, while in the FA13 control were found 48 compounds. However, the numbers of VOCs at the end of the fermentation process (144 h) increased for all samples. In detail, 46 compounds for CEPEC2002 SP, 43 for CEPEC2002 control, 42 for FA $13 \mathrm{~S}$ and 58 for FA13 control were found.

Regarding both hybrids, the profiles of aldehydes, ketones, pyrazines and esters were very similar. Despite the similarity in the presence/absence profiles, the percentages of volatile compounds were different, fluctuating throughout the fermentation. Acid and ester groups increased, while alcohols, aldehydes and

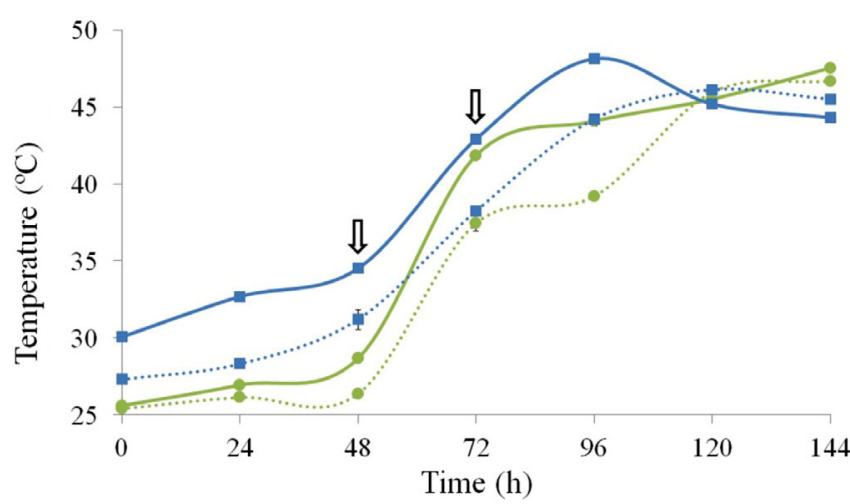

Figure 1. Evolution of temperature during fermentation under different conditions. CEPEC2002 ( $\square$ ), FA13 (๑). Inoculated (CEPEC2002 SP and FA13 S, continuous line) and spontaneous (CEPEC2002 and FA13, dotted line) fermentations. Mixing ( $($ ) of the mass was performed at 48 and $72 \mathrm{~h}$. 
Table 1. VOCs identified by HS-SPME GC-MS during cocoa beans fermentation from $0 \mathrm{~h}$ to $144 \mathrm{~h}$, and in chocolate samples (Ch), and reference flavour for compounds. Fill box means presence and open box absence of the compound

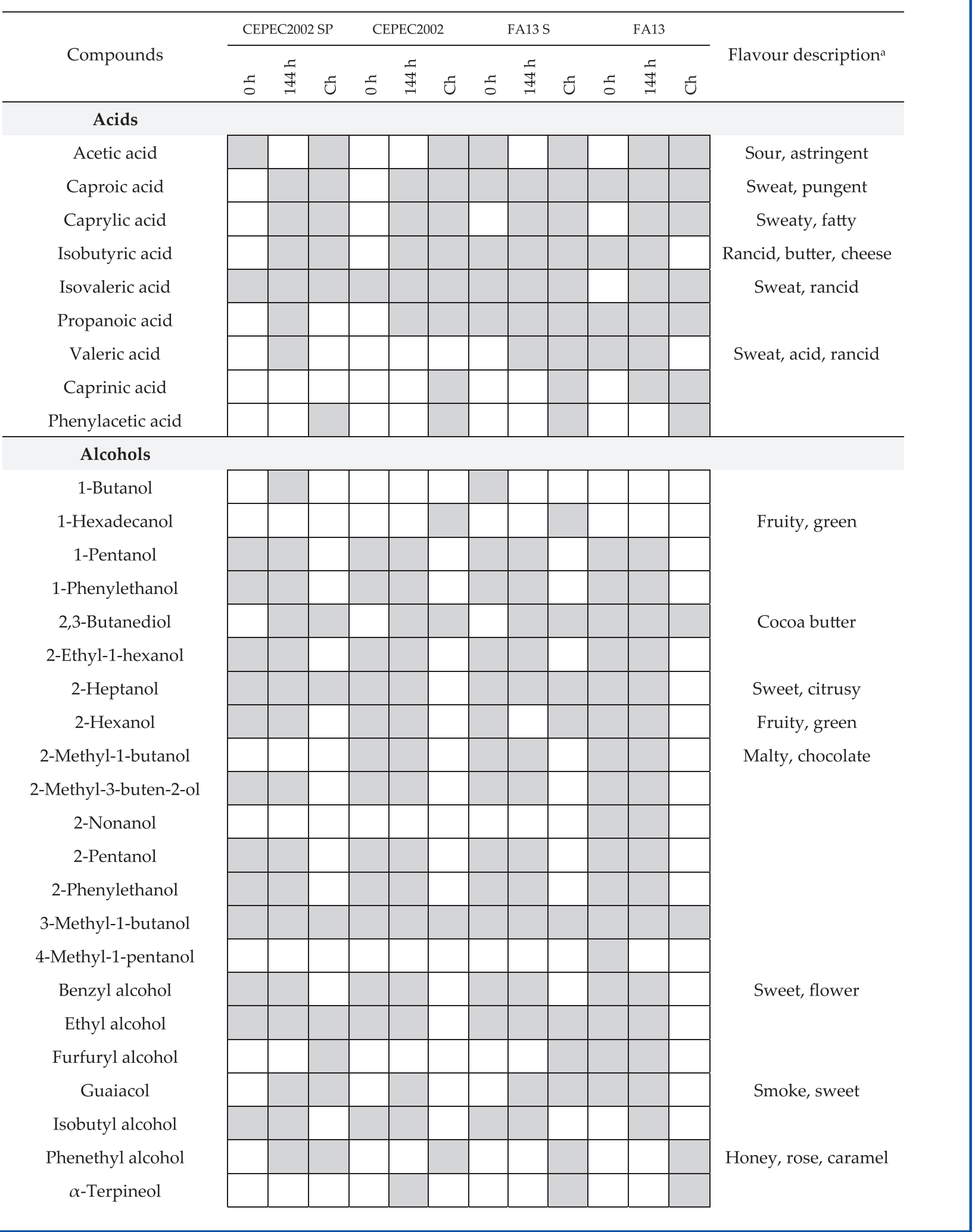


Table 1. Continued

\begin{tabular}{|c|c|c|c|c|c|c|c|c|c|c|c|c|c|}
\hline \multirow{3}{*}{ Compounds } & \multicolumn{3}{|c|}{ CEPEC2002 SP } & \multicolumn{3}{|c|}{ CEPEC2002 } & \multicolumn{3}{|c|}{ FA13 S } & \multicolumn{3}{|c|}{ FA13 } & \multirow{3}{*}{ Flavour descriptiona } \\
\hline & & ᄃ & & & 工ᄃ & & & ᄃ & & & ᄃ & & \\
\hline & ᄃ & $\underset{J}{J}$ & $\tilde{U}$ & $\frac{1}{0}$ & $\underset{J}{J}$ & $\tilde{U}$ & 동 & $\underset{J}{ }$ & $\tilde{U}$ & $\frac{1}{0}$ & $\underset{J}{J}$ & U & \\
\hline
\end{tabular}

Aldehydes and Ketones

(E)-2-butenal

1-phenylethanone

2,3-Butanedione

2,3-Pentanedione

2-Acetylfuran

2-Furaldehyde

2-Heptadecanone

2-Heptanone

2-Methyl-2-butenal

2-Octanone

2-Pentanone

2-Pentylfuran

2-Propanone

2-Pyrrolidone

2-Vinylfuran

3-Methyl-2(5H)-furanone

3-Methyl-2-butenal

3-Methylbutanal

5-Methyl-2-hexanone

Acetaldehyde

Acetoin

Benzaldehyde

Benzeneacetaldehyde

Butyrolactone

Hexanal

Pentanal

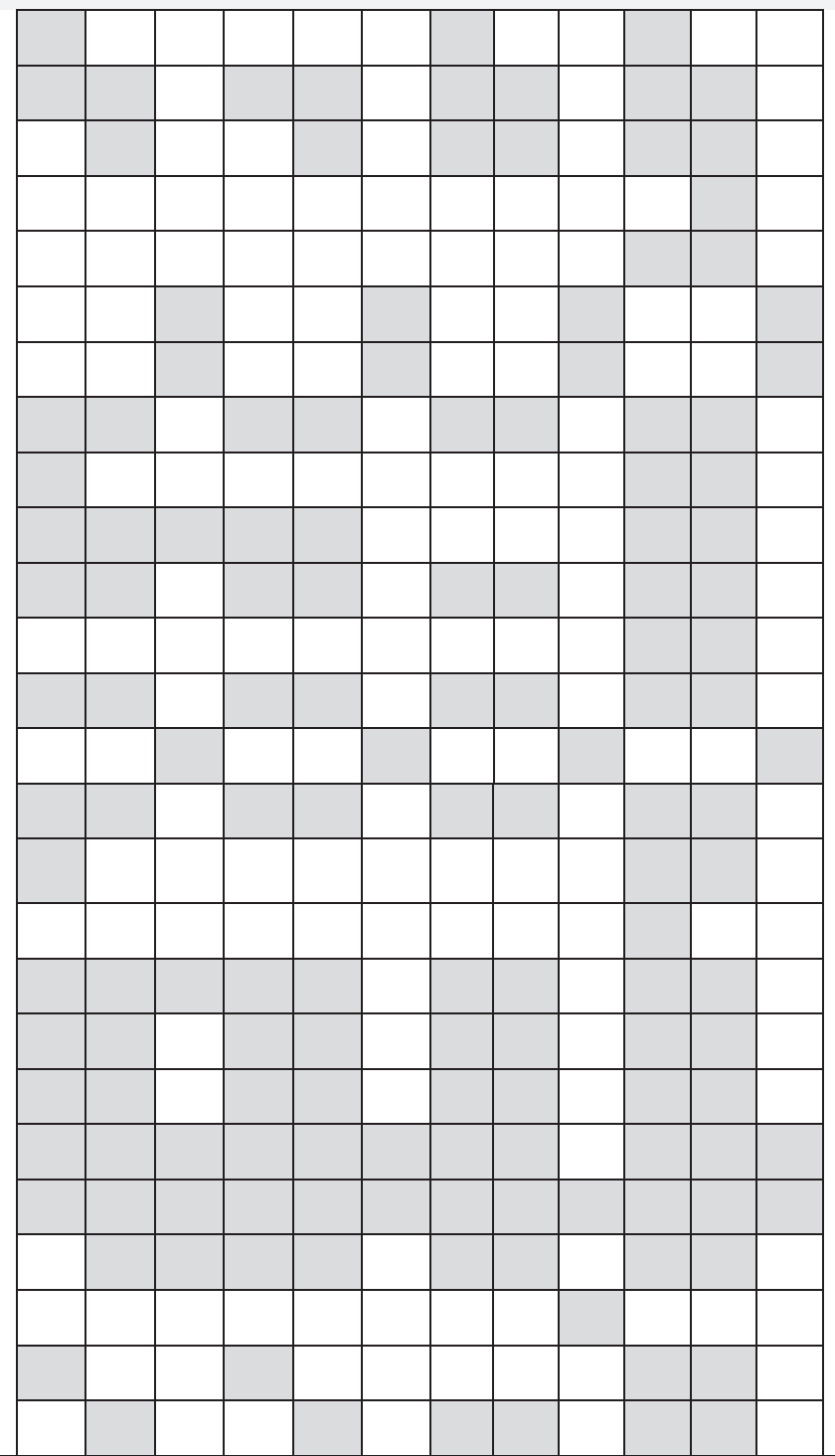

Butter, cream

Bitter

Esters

2-Pentyl acetate

2-phenylethyl isobutyrate

Allyl acetate

Amyl acetate

Ehtyl acetate

Ethyl benzoate

Ethyl caproate

Ethyl caprylate

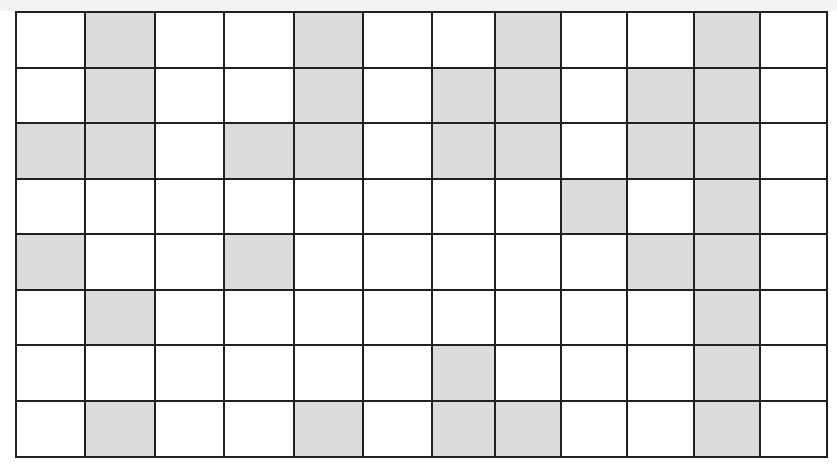

Fruity

Fruity, banana

Fruity, flowery 
Table 1. Continued

\begin{tabular}{|c|c|c|c|c|c|c|c|c|c|c|c|c|c|}
\hline \multirow{3}{*}{ Compounds } & \multicolumn{3}{|c|}{ CEPEC2002 SP } & \multicolumn{3}{|c|}{ CEPEC2002 } & \multicolumn{3}{|c|}{ FA13 S } & \multicolumn{3}{|c|}{ FA13 } & \multirow{3}{*}{ Flavour description $^{a}$} \\
\hline & & ᄃ & & & 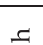 & & & $工$ & & & $工$ & & \\
\hline & క & 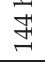 & ש & કี & $\underset{H}{J}$ & $\tilde{U}$ & કิ & 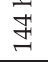 & ש & s. & 壱 & ש & \\
\hline \multicolumn{14}{|l|}{ Esters } \\
\hline \multicolumn{14}{|l|}{ Ethyl myristate } \\
\hline \multicolumn{14}{|l|}{ Ethyl phenylacetate } \\
\hline \multicolumn{14}{|l|}{ Ethyl pyruvate } \\
\hline \multicolumn{14}{|l|}{ Isoamyl acetate } \\
\hline \multicolumn{14}{|l|}{ Dibutyl phthalate } \\
\hline \multicolumn{14}{|l|}{ Diisobutyl phthalate } \\
\hline \multicolumn{14}{|l|}{ Ethyl caprate } \\
\hline \multicolumn{14}{|l|}{ Ethyl laurate } \\
\hline \multicolumn{14}{|l|}{ Ethyl palmitate } \\
\hline \multicolumn{14}{|l|}{ Methyl palmitate } \\
\hline \multicolumn{14}{|l|}{ Phenylethyl acetate } \\
\hline \multicolumn{14}{|c|}{ Others (Pyrazines, pyrroles and terpenes) } \\
\hline \multicolumn{14}{|l|}{ Tetramethyl-pyrazine } \\
\hline \multicolumn{14}{|l|}{ Trimethyl-pyrazine } \\
\hline \multicolumn{14}{|r|}{ Chocolate, hazelnut } \\
\hline Linalool & & & & & & & & & & & & & Flower, lavender \\
\hline
\end{tabular}

ketones decreased in different proportion for all samples, as shown in Fig. 2.

Concerning the chocolate samples, 29 compounds were identified in spontaneous fermentations (CEPEC2002 and FA13). Chocolates from CEPEC2002 inoculated with a mix of the two yeasts showed 30 identified compounds, while chocolates produced from inoculated FA13 presented a total of 35 VOCs. The occurrence of acids, esters and other compounds (pyrazines, pyrroles and terpenes) gradually increased during the whole process, from fermentation to chocolate, for all samples; while the occurrence of alcohols, aldehydes and ketones decreased, as observed in Fig. 2.

\section{MALDI-TOF MS: protein degradation kinetics and clustering}

Protein extracts were quantified using Bradford's method and the results are presented in Table 2 . For all fermentations, protein concentrations decreased approximately half way from the beginning to the end of fermentation. The greatest protein degradation was observed in the CEPEC2002 spontaneous fermentation, a reduction of $0.42 \mathrm{mg}$ of protein per millilitre of extract. Protein samples were then analysed using the MALDI-TOF MS technique. Mass spectra obtained for each sample allowed the determination of minimum and maximum molecular masses $(\mathrm{m} / \mathrm{z})$ and the total mass peaks for each sample (Table S2, supporting information).
The peak matching operation in Mass-up software generated a list with 131 ion peaks of different $m / z$ values (data not shown). Only 3 out of 131 peaks were common among all samples $(\mathrm{m} / \mathrm{z}$ 2818.716, 4195.56 and 9538.966). Ion peaks with mass values $\mathrm{m} / \mathrm{z} 2723.138,3127.244$ and 3735.043 were found only in CEPEC2002 inoculated with S. cerevisiae and P. kluyveri.

A greater number of ion peaks with different $m / z$ values was observed for FA13 S (2103.681, 2302.024, 2879.490, 2929.855, $3256.854,3421.062$ and 4797.277). In Fig. 3 can be observed a clustering in terms of similarity of the samples using data of presence and absence of the generated peak list in Mass-up software.

\section{Sensorial analysis}

Both the acceptance test and CATA questionnaire allowed differentiation between the chocolates produced from spontaneous and inoculated fermentations. The parameters used in CATA questionnaire analysis were focused for determining if the flavours of the chocolates were bitter, sweet, coffee and nutty. Judges indicated which attributes better described the chocolate samples, and the results are shown in Fig. 4.

Although there were no significant differences $(P<0.5$, by Tukey's test) between samples from inoculated (CEPEC2002 SP and FA13 S) and non-inoculated fermentations (CEPEC2002 and FA13), pleasant notes were predominantly perceived in chocolates from CEPEC2002 SP and FA13 S. 

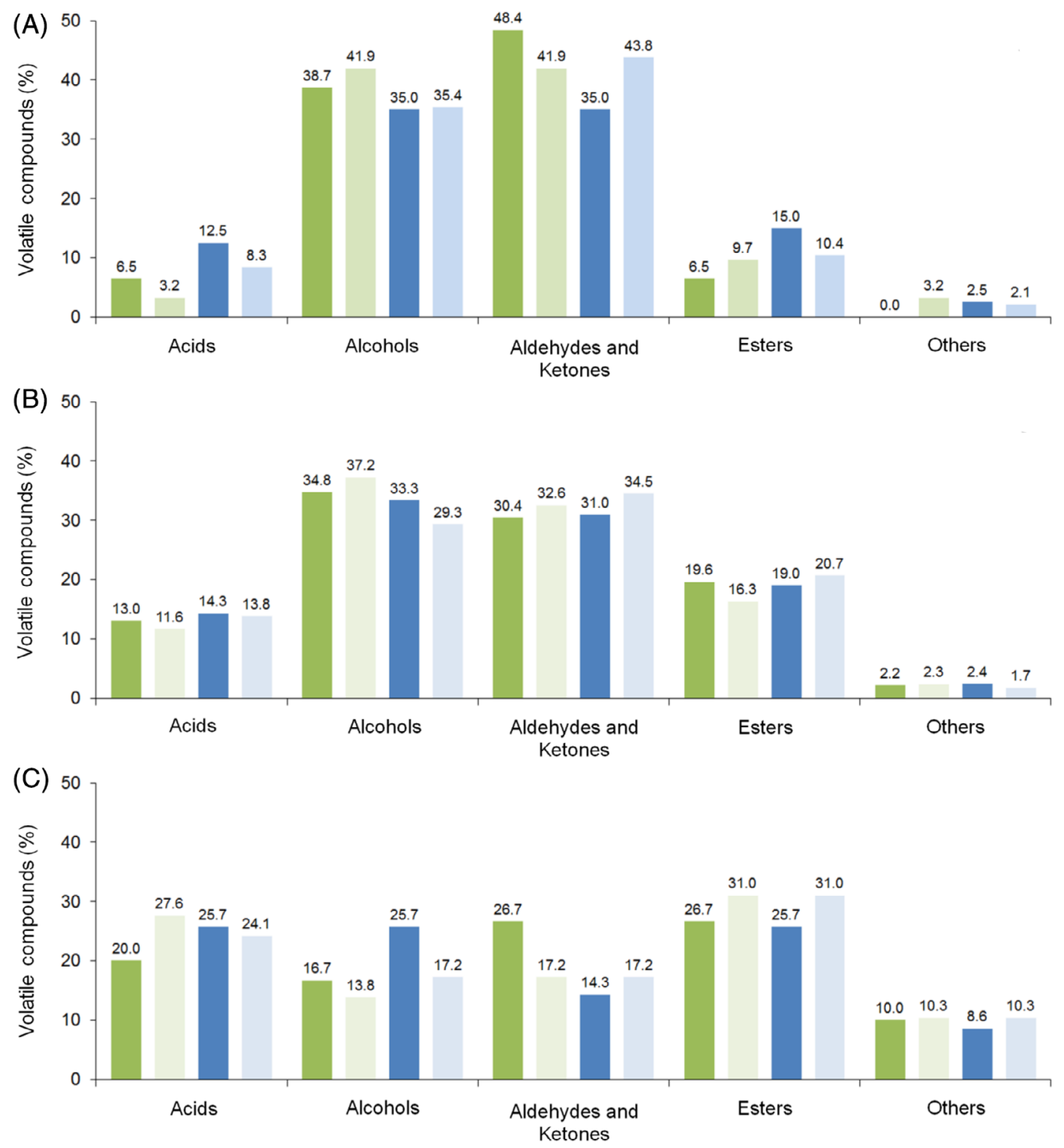

Figure 2. VOCs identified using HS-SPME GC-MS during cocoa bean fermentations for (A) $0 \mathrm{~h}$ and (B) $144 \mathrm{~h}$ and chocolate samples (C) of CEPEC2002 SP ( $)$, CEPEC2002 control ( ), FA13 S ( $\square$ ) and FA13 control ( ).

Table 2. Protein quantification by Bradford's method for inoculated and spontaneous fermentations at beginning and at end of process

\begin{tabular}{lc} 
Sample & Extract $\left(\mathrm{mg} \mathrm{mL}^{-1}\right)$ \\
\hline CEPEC2002 SP 0 h & $0.71 \pm 0.01^{\mathrm{a}}$ \\
CEPEC2002 SP 144 h & $0.39 \pm 0.01^{\mathrm{b}}$ \\
CEPEC2002 0 h & $0.76 \pm 0.05^{\mathrm{a}}$ \\
CEPEC2002 144 h & $0.34 \pm 0.01^{\mathrm{b}}$ \\
FA13 S 0 h & $0.73 \pm 0.00^{\mathrm{a}}$ \\
FA13 S 144 h & $0.38 \pm 0.05^{\mathrm{b}}$ \\
FA13 0 h & $0.64 \pm 0.03^{\mathrm{a}}$ \\
FA13 144 h & $0.33 \pm 0.03^{\mathrm{b}}$
\end{tabular}

In each hybrid, values followed by different letters are different at the $5 \%$ level of significance by ANOVA test.
Samples from CEPEC2002 SP were described as bitter and sweeter, with a lower perception of an undesirable sour taste. In contrast, the chocolates from FA13 S were perceived as sourer, fruity, sweetness and less astringent than chocolates from spontaneous fermentation.

\section{DISCUSSION}

Temperature is a driving factor for chocolate manufacture. This parameter may fluctuate due to metabolic reactions carried out by microbiota harboured in cocoa beans. ${ }^{35}$ Temperature changes were detected for all the various fermentations performed in the present study. However, a considerable increase in temperature was noted between 48 and $72 \mathrm{~h}$ in inoculated fermentations.

The addition of a yeast cocktail may have potentiated alcoholic fermentation of the pulp sugars, producing ethanol. This consequently potentiated the next reaction in which $A A B$ oxidize the alcohol formed, first into acetic acid and then to $\mathrm{CO}_{2}$ and $\mathrm{H}_{2} \mathrm{O}$. 


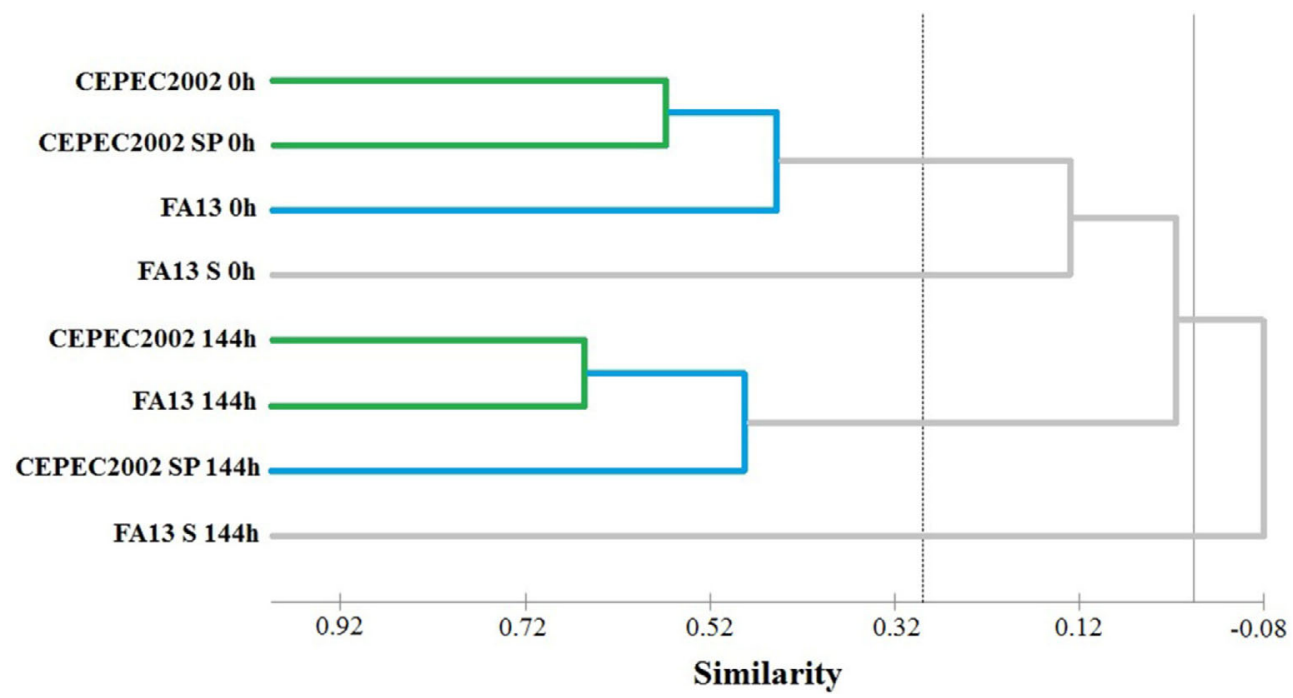

Figure 3. AHC based on presence and absence of mass peaks with different $m / z$ values.
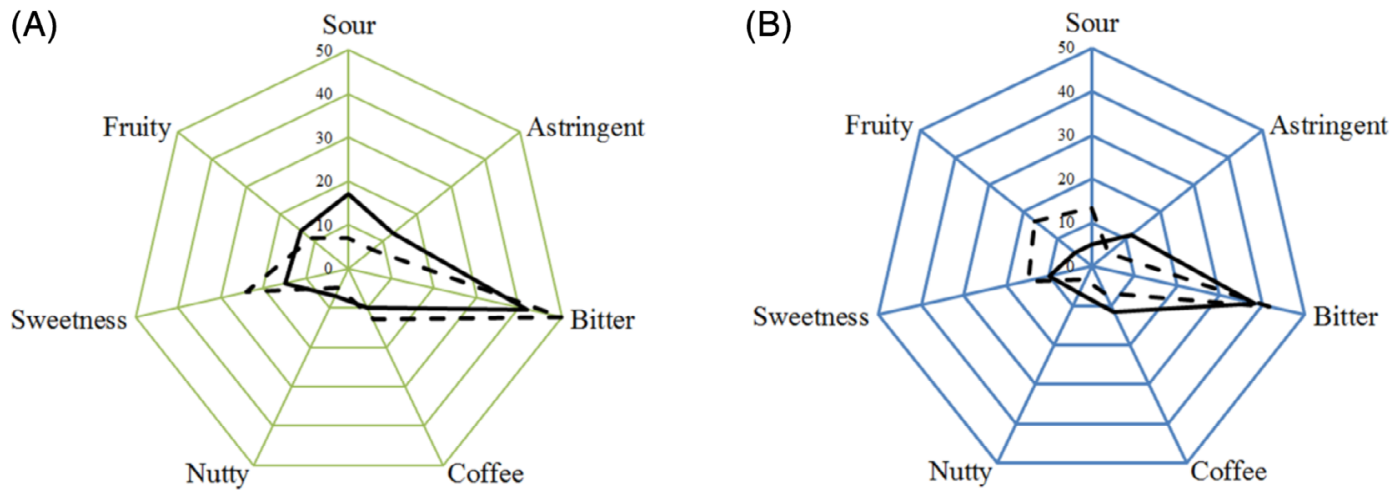

Figure 4. Results of CATA questionnaire analysis regarding the flavour of chocolates produced with spontaneous fermentation (solid line) and fermentation with a yeasts starter culture (dashed line). (A) CEPEC2002 and (B) FA13.

Table 3. Scores of acceptance test for chocolate samples of each fermentation, with and without inoculation

\begin{tabular}{|lc|} 
Chocolate sample & Acceptance test \\
\hline CEPEC2002 SP & $7.27^{\mathrm{a}}$ \\
CEPEC2002 & $6.79^{\mathrm{b}}$ \\
FA13 S & $7.32^{\mathrm{a}}$ \\
FA13 & $6.83^{\mathrm{b}}$ \\
\hline
\end{tabular}

Values followed by the same letter in the same row are not different at the $5 \%$ level of significance by Tukey's test.

This exothermic reaction can lead to rising cocoa bean mass heap temperature. ${ }^{6}$ Also, a temperature increase occurred simultaneously with performing a turning ofbean mass (e.g. 48 and $72 \mathrm{~h}$ ). Aeration stimulated the exothermic reactions carried out by aerobic $A A B .^{36}$

Addition of a starter yeast cocktail can drive pleasant metabolites in raw cocoa. Some of the volatiles found in inoculated samples have been assigned to $P$. kluyveri metabolism (e.g. benzaldehyde, 1-butanol, phenylethyl alcohol) and $S$. cerevisiae metabolism (3-methyl-1-butanol, 2-phenylethanol, 2-pentanone). ${ }^{13}$
As is evident from Table 1, some identified alcohols are responsible for conferring sweet, fruity, malty, honey and caramel flavours to the cocoa final product. ${ }^{7,37,38}$ In the present study alcohols with pleasant notes, such as 2-phenylethanol, 2,3-butanediol, 2-heptanol and benzyl alcohol, have been detected.

Conversely, the occurrence of some VOCs (e.g. phenol, 2-ethyl3,5-dimethylpyrazine, ethyl heptanoate and so forth) that may confer unpleasant flavour must be avoided. ${ }^{7}$ Increasing acid concentration during the fermentation process can generate perceptions of sour taste (Fig. 2). Chocolate from FA13 S contained a higher number of organic acids identified by GC-MS (Table 1), which may have given rise to the sour characteristic described by judges (Fig. 4). On the other hand, chocolate from CEPEC2002 SP had a decreased amount of acids, which could be reflected in the sour taste perception (Fig. 4). Overall, the inoculation process improved the chocolate sensorial qualities, as translated in chocolates being judged more acceptable (Table 3).

Several studies showed that yeast inoculation in cocoa fermentation modifies the chemical composition of fermented beans and consequently the chocolate sensorial profiles. ${ }^{21,39,40}$ Batista et $a l^{19}$ reported a yeast cocktail applied in cocoa fermentation (S. cerevisiae, P. kluyveri and Hanseniaspora uvarum). Yeast inoculation accelerated carbohydrate consumption and ethanol 
production during the process. Also, judges reported stronger coffee and sour attributes of chocolate produced from the inoculated assay. ${ }^{19}$

According to previous work, S. cerevisiae and P. kluyveri probably inhibit the growth of another yeast (H. uvarum) used as inoculum. This was justified based on the ability of $S$. cerevisiae and $P$. kluyveri in producing toxins against other yeast genera. ${ }^{41}$ Furthermore, other studies have mentioned that VOCs play a key role in microbial interaction avoiding a growth of competitor microorganisms. $^{42,43}$ Understanding VOCs released during cocoa fermentation would also enlighten microbial succession that occurs during this process.

Crafack et $a l^{40}$ analysed the impact of starter cultures on sensory attributes of chocolate. Fermentation inoculated with $P$. kluyveri in association with Kluyveromyces marxianus produced chocolates characterised as fruity, acid and bitter. P. kluyveri is considered a highly aromatic yeast, while $S$. cerevisiae, besides producing aromatic compounds, is considered a large alcohol producer and highly resistant to environmental conditions (e.g. $\mathrm{pH}$, temperature, ethanol concentration). ${ }^{4}$

The proper performance of the fermentative process is pivotal for downstream steps (e.g. drying, roasting and conching) and hence for flavour compound formation. ${ }^{44}$ Pyrazine compounds are formed mainly during the cocoa bean roasting process due to Maillard reaction. Moreover, pyrazine production has also been linked to Bacillus strains. ${ }^{45}$

Tetramethylpyrazine and trimethylpyrazine have been detected in all chocolate samples, although during fermentation ( 0 and $144 \mathrm{~h}$ ) these compounds were not detected (Table 1). Tetramethylpyrazines have been reported in cocoa aroma, being related to pleasant flavour notes (e.g., nutty, roasted and chocolate).$^{39}$ The absence of Bacillus spp. and the temperatures reached in the fermentation have been reported as possible reasons for the absence of these compounds. ${ }^{46}$

The aroma admixture which characterises chocolate is not formed only by the presence of volatile compounds. As mentioned previously, the onset of proteolytic processes inside the beans occurs after embryo death due mainly to yeast action. Some studies confirmed the presence of endoprotease and carboxypeptidase. ${ }^{47,48}$ Both these proteases are composed mainly of albumin and vicilin-class (7S) globulin, which can degrade the majority of protein content inside beans during fermentation. ${ }^{49,50}$

Free amino acids and hydrophilic peptides derived from the vicilin-class (7S) globular storage protein are necessary for the formation of the cocoa-specific flavours during the roasting process. $^{51,52}$

In the present study, as an effect of the proteolytic processes inside the beans, the content of total protein decreased during all fermentations, both inoculated and spontaneous ones (Table 2). Furthermore, initial and final times of fermentation showed different protein profiles, as presented in Table 2.

Using the MALDI-TOF MS technique, it was possible to determine more precisely the pool of different peptide molecular masses and generate more adequate protein profiles. The MALDI-TOF MS technique delivered only qualitative information about proteins. Hence the lack of quantification of each ion peak did not allow an in-depth determination of the protein degradation dynamics. However, in agreement with sensorial analysis results, the yeast inoculation triggered modification in protein profiles.

According to the results observed in the AHC graph (Fig. 3), it can be possible to identify similarities among protein profiles of the inoculated fermentations at the end of the process (144 h). In addition, differences between the fermentation at $0 \mathrm{~h}$ can be explained by microbiota intrinsic to each hybrid. Overall, to clarify the influence of the protein/peptide profiles and VOCs on the final chocolate flavour, a clear need for exhaustive analysis with complementary techniques such as MALDI-TOF MS/MS is here highlighted.

This study showed that inoculation with $P$. kluyveri and S. cerevisiae yeast starter can influence the composition of VOCs and sensory profile of chocolates, enhancing the cocoa quality. Moreover, MALDI-TOF MS results corroborated that protein profiles also changed with fermentations.

Regarding the results of the CATA questionnaire, use of S. cerevisiae CCMA-UFLA 0200 as single inoculum showed a greater effect on changing chocolate sensory attributes. Although, based on the scores of the acceptance test, both chocolates produced from inoculated fermentations were most appreciated by judges.

A further in-depth investigation would be necessary to understand the modulation of each VOC throughout the fermentation process, as well as the protein degradation dynamics during inoculated fermentation.

\section{AUTHOR CONTRIBUTIONS}

R.S., N.L. and C.S. developed the project, planned the experiments and drafted the paper and made the final revision of the paper; I.M. performed the experiments; I.M., J.C. and L.V. analysed the data and wrote the paper.

\section{ACKNOWLEDGEMENTS}

The authors thank CNPq/Brazil, FAPEMIG/Brazil and CAPES/Brazil for scholarships, and Fazendas Reunidas Vale do Juliana (Bahia, Brazil). CS thanks Universidad de La Frontera/Chile for partial funding from Project PIA19-0001.

\section{CONFLICTS OF INTEREST}

Nothing to declare.

\section{SUPPORTING INFORMATION}

Supporting information may be found in the online version of this article.

\section{REFERENCES}

1 Vásquez ZS, Carvalho Neto DP, Pereira GVM, Vandenberghe LPS, de Oliveira PZ, Tiburcio PB et al., Biotechnological approaches for cocoa waste management: a review. Waste Manag 90:72-83 (2019). https://doi.org/10.1016/j.wasman.2019.04.030.

2 Voora V, Bermúdez S, Larrea C, Global Market Report. Sustainable Commodities Marketplace Series 62 (2019). http://www.jstor.com/stable/ resrep22025.

3 Muñoz MS, Cortina JR, Vaillant FE and Parra SE, An overview of the physical and biochemical transformation of cocoa seeds to beans and to chocolate: flavor formation. Crit Rev Food Sci Nutr 60: 1593-1613 (2020). https://doi.org/10.1080/10408398.2019.1581726.

4 Schwan RF and Fleet GH eds, Cocoa and Coffee Fermentations. CRC Press, Boca Raton, FL (2014).

5 Alayo EMC, Vásquez GI, Siche R and Toro FPC, Formation of aromatic compounds precursors during fermentation of Criollo and Forastero cocoa. Heliyon 5:e01157 (2019). https://doi.org/10.1016/j.heliyon. 2019.e01157. 
6 Schwan RF and Wheals $A E$, The microbiology of cocoa fermentation and its role in chocolate quality. Crit Rev Food Sci Nutr 44:205-221 (2004). https://doi.org/10.1080/10408690490464104.

7 Campos JR, Buendía HBE, Avila IO, Cervantes EL and Flores MEJ, Dynamics of volatile and non-volatile compounds in cocoa (Theobroma cocoa L.) during fermentation and drying process using principal components analysis. Food Res Int 44:250-258 (2011). https:// doi.org/10.1016/j.foodres.2010.10.028.

8 Ho VTT, Zhao J and Fleet G, Yeasts are essential for cocoa bean fermentation. Int J Food Microbiol 174:72-87 (2014). https://doi.org/10. 1016/j.jijfoodmicro.2013.12.014.

9 Serra JL, Moura FG, Pereira GVDM, Soccol CR, Rogez H and Darnet S, Determination of the microbial community in Amazonian cocoa bean fermentation by Illumina-based metagenomic sequencing. LWT Food Sci Technol 106:229-239 (2019). https://doi.org/10.1016/ j.Iwt.2019.02.038.

10 Ho VTT, Fleet G and Zhao J, Unravelling the contribution of lactic acid bacteria and acetic acid bacteria to cocoa fermentation using inoculated organisms. Int J Food Microbiol 279:43-56 (2018). https://doi. org/10.1016/j.ijfoodmicro.2018.04.040.

11 Ouattara HD, Ouattara HG, Droux M, Reverchon S, Nasser W and Niamke SL, Lactic acid bacteria involved in cocoa beans fermentation from Ivory Coast: species diversity and citrate lyase production. Int J Food Microbiol 256:11-19 (2017). https://doi.org/10.1016/j. ijfoodmicro.2017.05.008.

12 Viesser JA, Pereira GVM, Neto DPC, Vandenberghe LP, Azevedo V, Brenig $B$ et al., Exploring the contribution of fructophilic lactic acid bacteria to cocoa beans fermentation: isolation, selection and evaluation. Food Res Int 136:109478 (2020). https://doi.org/10.1016/j. foodres.2020.109478.

13 Clair BJA, Koné MK, Kouamé K, Lahon MC, Berthiot L, Durand N et al., Effect of aroma potential of Saccharomyces cerevisiae fermentation on the volatile profile of raw cocoa and sensory attributes of chocolate produced thereof. Eur Food Res Technol 245:1459-1471 (2019). https://doi.org/10.1007/s00217-018-3181-6.

14 Gutierrez JM, Botta C, Ferrocino I, Giordano M, Bertolino M, Dolci P et al., Dynamics and biodiversity of bacterial and yeast communities during fermentation of cocoa beans. Appl Environ Microbiol 84:1-17 (2018). https://doi.org/10.1128/AEM.01164-18.

15 Romanens E, Näf R, Lobmaier T, Pedan V, Leischtfeld SF, Meile L et al., A lab-scale model system for cocoa bean fermentation. Appl Microbiol Biotechnol 102:3349-3362 (2018). https://doi.org/10.1007/s00253018-8835-6.

16 Hamdouche Y, Christophe J, Lebrun M, Guehi T, Boulanger R, Teyssier C et al., Impact of turning, pod storage and fermentation time on microbial ecology and volatile composition of cocoa beans. Food Res Int 119 477-491 (2019). https://doi.org/10.1016/j.foodres.2019.01.001.

17 Hernández CF, Gutierrez JM and Ferrocino I, The challenges and perspectives of the selection of starter cultures for fermented cocoa beans. Int J Food Microbiol 301:41-50 (2019). https://doi.org/10. 1016/j.jijfoodmicro.2019.05.002.

18 John WA, Böttcher NL, Aßkamp M, Bergounhou A, Kumari N, Ho P et al., Forcing fermentation: profiling proteins, peptides and polyphenols in lab-scale cocoa bean fermentation. Food Chem 278:786-794 (2018). https://doi.org/10.1016/j.foodchem.2018.11.108.

19 Batista NN, Ramos CL, Ribeiro DD, Pinheiro ACM and Schwan RF, Dynamic behavior of Saccharomyces cerevisiae, Pichia kluyveri and Hanseniaspora uvarum during spontaneous and inoculated cocoa fermentations and their effect on sensory characteristics of chocolate. LWT Food Sci Technol 63:221-227 (2015). https://doi.org/10. 1016/j.lwt.2015.03.051.

20 Gutierrez JM, Pereira LB, Ferrocino I and Cocolin L, Traceability of functional volatile compounds and its potential health benefits. Nutrients 11:2-23 (2019). https://doi.org/10.3390/nu11040884.

21 Moreira IMV, Vilela LF, Miguel MGCP, Santos C, Lima N and Schwan RF, Impact of a microbial cocktail used as a starter culture on cocoa fermentation and chocolate flavour. Molecules 22:766 (2017). https:// doi.org/10.3390/molecules22050766.

22 Ramos CL, Dias DR, Miguel MG d CP and Schwan RF, Impact of different cocoa hybrids (Theobroma cacao L.) and S. cerevisiae UFLA CA11 inoculation on microbial communities and volatile compounds of cocoa fermentation. Food Res Int 64:908-918 (2014). https://doi. org/10.1016/j.foodres.2014.08.033.

23 Moreira N, Lopes P, Cabral M and Pinho PG, HS-SPME/GC-MS methodologies for the analysis of volatile compounds in cork material. Eur
Food Res Technol 242:457-466 (2016). https://doi.org/10.1007/ s00217-016-2636-x.

24 Petisca C, Palacios TP, Farah A, Pinho O and Ferreira I, Furans and other volatile compounds in ground roasted and espresso coffee using headspace solid-phase microextraction: effect of roasting speed. Food Bioprod Process 91:233-241 (2013). https://doi.org/10.1016/j. fbp.2012.10.003.

25 Voigt J and Biehl B, The major seed proteins of Theobroma cacao L. Food Chem 47:145-151 (1993). https://doi.org/10.1016/0308-8146 (93) $90236-9$.

26 Bradford MM, A rapid and sensitive for the quantitation of microgram quantities of protein utilizing the principle of protein-dye binding. Anal Biochem 72:248-254 (1976). https://doi.org/10.1016/00032697(76)90527-3.

27 Miguel MGCP, Reis VVC, Efraim P, Santos C, Lima N and Schwan RF, Cocoa fermentation: microbial identification by MALDI-TOF MS and sensory evaluation of produced chocolate. LWT Food Sci Technol 77:351-362 (2017). https://doi.org/10.1016/j.lwt.2016.11.076.

28 Neto RL, Santos C, Lima N, Sampaio P, Pais C and Neves RP, Application of MALDI-TOF MS for requalification of a Candida clinical isolates culture collection. Braz J Microbiol 45:515-522 (2014). https://doi. org/10.1590/s1517-83822014005000044.

29 Oliveira M, Santos C, Sampaio P, Romeo O, Paes RA, Pais C et al., Development and optimization of a new MALDI-TOF protocol for identification of the Sporothrix species complex. Res Microbiol 166:102-110 (2015). https://doi.org/10.1016/j.resmic.2014.12.008.

30 Matos AMF, Moreira LM, Barczewski BF, Matos LX, Oliveira JBV, Pimentel MIF et al., Identification by MALDI-TOF MS of Sporothrix brasiliensis isolated from a subconjunctival infiltrative lesion in an immunocompetent patient. Microorganisms 8:22-33 (2020). https://doi.org/10.3390/microorganisms8010022.

31 Paziani MH, Carvalho LT, Melhem MSC, Almeida MTG, Silva MENB, Martinez $\mathrm{R}$ et al., First comprehensive report of clinical Fusarium strains isolated in the state of Sao Paulo (Brazil) and identified by MALDI-TOF MS and molecular biology. Microorganisms 8:66 (2020). https://doi.org/10.3390/microorganisms8010066.

32 Fernández HL, Santos HM, Capelo JL, Riverola FF, Peña DG and Jato MR, Mass-up: an all-in-one open software application for MALDI-TOF mass spectrometry knowledge discovery. BMC Bioinf 16:1-12 (2015). https://doi.org/10.1186/s12859-015-0752-4.

33 Moreira IMV, Vilela LF, Santos C, Lima N and Schwan RF, Volatile compounds and protein profiles analyses of fermented cocoa beans and chocolates from different hybrids cultivated in Brazil. Food Res Int 109:196-203 (2018). https://doi.org/10.1016/j.foodres.2018.04.012.

34 Stone HS and Sidel JL eds, Sensory Evaluation Practices. Academic Press, Los Angeles, CA (2004).

35 Rodriguez-Campos J, Escalona-Buendía HB, Contreras-Ramos SM, Orozco-Avila I, Jaramillo-Flores E and Lugo-Cervantes E, Effect of fermentation time and drying temperature on volatile compounds in cocoa. Food Chem 132:277-288 (2012). https://doi.org/10.1016/j. foodchem.2011.10.078.

36 Passos FML, Lopez AS and Silva DO, Aeration and its influence on the microbial sequence in cacao fermentations in Bahia, with emphasis on lactic acid bacteria. J Food Sci 49:1470-1474 (1984). https://doi. org/10.1111/j.1365-2621.1984.tb12823.x.

37 Camu N, de Winter T, Addo SK, Takarama JS, Bernaert H and de Vuyst L, Fermentation of cocoa beans: influence of microbial activities and polyphenol concentrations on the flavour of chocolate. J Sci Food Agric 88:2288-2297 (2008). https://doi.org/10.1002/jsfa.3349.

38 Marseglia A, Musci M, Rinaldi M, Palla G and Caligiani A, Volatile fingerprint of unroasted and roasted cocoa beans (Theobroma cacao L.) from different geographical origins. Food Res Int 132:101-109 (2020). https://doi.org/10.1016/j.foodres.2020.109101.

39 Rottiers H, Sosa DAT, de Winne A, Ruales J, de Clippeleer J, de Leersnyder I et al., Dynamics of volatile compounds and flavor precursors during spontaneous fermentation of fine flavor Trinitario cocoa beans. Eur Food Res Technol 245:1917-1937 (2019). https:// doi.org/10.1007/s00217-019-03307-y.

40 Crafack M, Keul H, Eskildsen CE, Petersen MA, Saerens S, Blennow A et al., Impact of starter cultures and fermentation techniques on the volatile aroma and sensory profile of chocolate. Food Res Int 63:306-316 (2014). https://doi.org/10.1016/j.foodres.2014.04.032.

41 Branco $P$, Francisco D, Chambon C, Hébraud M, Arneborg N, Almeida MG et al., Identification of novel GAPDH-derived antimicrobial peptides secreted by Saccharomyces cerevisiae and involved in 
wine microbial interactions. Appl Microbiol Biotechnol 98:843-853 (2014). https://doi.org/10.1007/s00253-013-5411-y.

42 Ruiz-Moyano S, Hernández A, Galvan Al, Córdoba MG, Casquete R, Serradilla MJ et al., Selection and application of antifungal VOCsproducing yeasts as biocontrol agents of grey mould in fruits. Food Microbiol 92:103556 (2020). https://doi.org/10.1016/j.fm.2020.103556.

43 Contarino R, Brighina S, Fallico B, Cirvilleri G, Parafati L and Restuccia C, Volatile organic compounds (VOCs) produced by biocontrol yeasts. Food Microbiol 82:70-74 (2019). https://doi.org/10.1016/j.fm.2019.01.008.

44 Jinap S, Ikrawan Y, Bakar J, Saari N and Lioe HN, Aroma precursors and methylpyrazines in underfermented cocoa beans induced by endogenous carboxypeptidase. J Food Sci 73:H141-H147 (2008). https://doi.org/10.1111/j.1750-3841.2008.00858.x.

45 Oracz $J$ and Nebesny E, Effect of roasting parameters on the physicochemical characteristics of high-molecular-weight Maillard reaction products isolated from cocoa beans of different Theobroma cacao L. groups. Eur Food Res Technol 245:111-128 (2019). https://doi. org/10.1007/s00217-018-3144-y.

46 Jinap S, Harun SM and Ghazali NM, Formation of methyl pyrazine during cocoa bean fermentation. Int J Trop Agric Sci 17:27-32 (1994).

47 Voigt J, Biehl B, Heinrichs H, Kamaruddin S, Marsoner GG and Hugi A, In-vitro formation of cocoa-specific aroma precursors: aroma-related peptides generated from cocoa-seed protein by co-operation of an aspartic endoprotease and a carboxypeptidase. Food Chem 49:173-180 (1994). https://doi.org/10.1016/0308-8146(94)90155-4.

48 Brunetto MR, Gallignani M, Orozco W, Clavijo S, Delgado Y, Ayala C et al., The effect of fermentation and roasting on free amino acids profile in Criollo cocoa (Theobroma cacao L.) grown in Venezuela. Braz J Food Technol 23:1-12 (2020). https://doi.org/10.1590/19816723.15019.

49 Voigt $\mathrm{J}$ and Lieberei R, Biochemistry of cocoa fermentation, in Cocoa and Coffee Fermentation, ed. by Schwan RF and Fleet GH. CRC Press, Boca Raton, FL, pp. 193-227 (2014).

50 D'Souza RN, Grimbs A, Grimbs S, Behrends B, Corno M, Ullrich MS et al., Degradation of cocoa proteins into oligopeptides during spontaneous fermentation of cocoa beans. Food Res Int 109:506-516 (2018). https://doi.org/10.1016/j.foodres.2018.04.068.

51 Scalone GLL, Taube KT, de Meulenaer B, de Kimpe N, Wöstemeyer J and Voigt J, Cocoa-specific flavor components and their peptide precursors. Food Res Int 123:503-515 (2019). https://doi.org/10. 1016/j.foodres.2019.05.019.

52 Voigt J, Janek K, Taube KT, Niewienda A and Wöstemeyer J, Partial purification and characterization of the peptide precursors of the cocoaspecific aroma components. Food Chem 192:706-713 (2016). https://doi.org/10.1016/j.foodchem.2015.07.068. 